\title{
ESTRUCTURA DEMOGRAFICA DE LA SIERRA MINERA DE CARTAGENA (1900-1920)
}

Pedro M. ${ }^{a}$ Egea, Bruno

U. N. E. D. Cartagena

\section{INTRODUCCION}

En un estudio demográfico de la cuenca cartagenera no pueden separarse los términos municipales de La Unión y Cartagena, por hallarse el primero enclavado dentro del segundo y, precisamente, en la parte más antiguamente explotada del distrito. Como el municipio de La Unión ocupa una extensión de sólo 2.455 hectáreas frente al término cartagenero que mide 55.745 , siendo análogos en uno y otro la mayor parte de los yacimientos, se comprenderá que prepondere este últimọ nombre en el estudio general de la región que tiene por centro de su comercio y de sus actividades industriales el puerto más importante, en estos años, de la costa levantina.

La región así considerada se sitúa en el extremo SE de la provincia de Murcia, teniendo como límites, por el norte los términos municipales de Fuente-Alamo, de Murcia y de Pacheco; por el este y sur el mar Mediterráneo, y por el Oeste los términos de Fuente-Alamo y Mazarrón. La cuenca, propiamente dicha, comprende la zona montañosa que se extiende a levante de la ciudad de Cartagena hasta Cabo de Palos, formando una faja de unos. 25 kibómetros de largo, con un ancho medio de unos seis.

Aun cuando la parte montuoso ocupa un 70 por ciento aproximadamente de su superficie total, lo cual en otras regiones contribuye a la despoblación del suelo, en Cartagena resulta la densidad de población muy elevada debido al gran desarrollo al- 
canzado por la minería '. Esta población se acumulaba principalmente en la zona comprendida entre el puerto de Cartagena y Cabo de Palos, donde las explotaciones mineras alcanzaron mayor importancia. Además de la populosa ciudad de Cartagena,

1 Vide sintesis de la situación minera de la comarca a principios de siglo en IRS: Información sobre el trabajo en las minas a propósito de las peticiones que las sociedades obreras elevaron al Gobierno el año 1909. Imp. de la Suce. sora de M. Minuesa de los Ríos, Madrid, 1910, págs. 15-18, reeditado en la actualidad. MARVÁ, José, El trabajo en las minas, Zero, Madrid, 1970. Una visión de conjunto puede contemplarse en EgEA BRuno, Pedro M. ${ }^{a}$, Movimientos sociales en la sierra minera de Cartagena (1840-1923), Editora Regional, Murcia, 1984, 2 vols., en prensa. Del mismo autor, "El resurgir contemporáneo de la sierra cartagenera. Coordenadas socio-económicas de una fiebre minera (1840-11849)", en Anales de Historia contemporánea, 2, Murcia, 1983, págs. 97-121. "Esplendor y miseria de la minería cartagenera (1850-1855)", en Papeles del Departamento de Geografía, núm. 8, Murcia, 1978-79, págs. 207-228. "Estructura minera del distrito cartagenero. Acotaciones a una crisis (1861. 67)", en Papeles del Departamento de Geografia, Murcia, 1984, en prensa. Un modelo de economía sectorial: la minería cartagenera (1840-1923). "Estudios sobre Historia Económica contemporánea de la Región de Murcia", Murcia, 1983, págs. 117-142. "Movimiento obrero y crisis finisecular en el distrito minero de Cartagena (1895-1898)", en Anales de la Universidad de Murcia, Facultad de Filosofía y Letras, vol. XXXVIII, núm. 4, Murcia, 1979-80, págs. 3-27. "Coyuntura minera y variables sociométricas entre el proletariado del distrito de Cartagena (1916-1923)", en Anales de la Universidad de Murcia, Facultad de Letras, vol. XL, núms. 3-4, Murcia (1983), págs. 165-206. La crisis de 1917 en Cartagena y su distrito minero. Aproximación a la historia murciana contemporánea (1909-1923), tesis doctoral dirigida por Juan Bta. Vilar, Universidad de Murcia, 1982, inédita. Vide una ajustada síntesis de igual título en Bulletin du Départament de Recherches Hispaniques Pyrenaica, Pau, 1983, págs. 30 34. "El crac de la minería cartagenera (1914-1921)", en Bulletin du Départament de Recherches Hispaniques Pyrenaica, Pau, núm. 28, diciembre 1983, págs. 61-72. La minería cartagenera en torno a la Primera Guerra Mundial (1909-1923), publ. Universidad de Murcia, Murcia, 1983, 76 págs. En colaboración con VILAR, Juan Bta., "Explotación minera y conflictividad social en el distrito de Cartagena durante el Sexenio democrático (1868-1874)", en Anales de la Universidad de Murcia, Facultad de Letras, vol. XXXIX, núms. 2-3-4, Murcia, 1982, págs. 233-271. "Minería y sociedad en el distrito de Cartagena durante el Sexenio democrático (1868-1874)", en Hispania, t. XLII, Madrid, 1983, págs. 607-654. "Coyuntura económica y movimiento obrero en Cartagena durante la Restauración (1875-1902)", en Anales de Historia Contemporánea, núm. 3, Murcia, 1984, en prensa. Igualment resulta interesenta la consulta de EsteVAN SENIS, M. a Teresa, "La minería cartagenera 1840-1919. Aspectos económicos y sociales", en Hispania, núm. 101, págs. 61-96, y de la misma autora, "La explotación de la sierra de Cartagena (1840-1919)", en Saitabi, XVII, Valencia, 1967, págs. 211-234. VILAR, Juan Bta., "Los orígenes de la minería del plomo en el distrito de Cartagena (1840-1868)", en Bulletin du Départament de Recherches Hispaniques, 28, 1983, págs. 45-60. 
se halla en el centro de aquella zona y al pie mismo de la sierra la importante villa de La Unión, así como Portmán se sitúa en su extremo sur y en la misma costa. Al pie de la ladera norte de la cuenca se encuentran también los pueblos de Alumbres, del Algar, Beal, Estrecho y Llano de San Ginés, y numerosos caseríos diseminados por distintos puntos del distrito, como los de La Esperanza, Descargador, Los Blancos, San Ginés, La Jordana, Los Belones y otros.

\section{MARCO ECONOMICO}

A comienzos del siglo $\mathrm{XX}$ la cuenca cartagenera sufrirá las consecuencias económicas de la guerra europea, que se sobreimpusieron a una crisis latente de hondas raíces, provocada por la extremada división de la propiedad minera, el sistema de arriendos y subarriendos y la mezquindad de los procedimientos de explotación ${ }^{2}$.

Una industria aquejada de tantos males endémicos difícimente podría soportar con éxito la viólenta conmoción que supuso en todos los órdenes económicos la guerra del 14 al 18.

Recién iniciado el conflicto bélico nuestra minería, caracterizada por su exclusiva dependencia de los mercados extranjeros $^{3}$, padecerá un grave trastorno. El entonces inspector del trabajo de la región informará a la superioridad en términos pavorosos: "...Las casas fụndidoras de plomo y las retiradoras de las demás clases de mineral recibieron orden telegráfica de las respectivas empresas consumidoras del extranjero de suspender todas las operaciones" 4 .

2 Vide Egea Bruno, P. M., Movimientos sociales...

3 Consejo de Mineria, Estadística minera de España. Año 1914, Madrid, 1915, página 315.

4 IRS, Resumen de las informaciones de los inspectores de trabajo acerca de las consecuencias sufridas por las industrias de España con motivo del actual estado de guerra mundial, Imp. de la Sucesora de M. Minuesa de los Ríos, Madrid, 1914, págs. 71-72. 
La magnitud del problema quedará avalada por el paulatino abandono de las labores mineras. De las 1.151 minas que poseía. la cuenca en actividad antes del conflicto sólo se hallaban en explotación unas 400 y el paro laboral forzoso alcanzaba al 70 por ciento de los obreros 5 .

Fue la primera secuela de la contienda, aunque sólo un acto reflejo de autoprotección de los consumidores. A ella se unirían - sin solución de continuidad - toda una serie de circunstancias que determinarán el crac de la minería local.

En primer lugar el cierre de los créditos, crisis psicológica de temor ante la gravedad del conflicto que acababa de estallar'. Las consecuencias no se hicieron esperar. Moratorias por parte de nuestros principales mercados - Francia e Inglaterra-, supresión del giro internacional, caída en vertical de los valores extrajeros y, como resultado, la paralización de los negocios de exportación?.

Esta situación gravitará pesadamente sobre la industria cartagenera en una doble vertiente. De un lado, si nuestros exportadores podían llevar minerales y metales a los mercados tradicionales, serían a cobrar - fruto de las moratorias - una vez resta. blecida la normalidad. De otro, en agosto de 1914, el Banco de España envió circulares a todas sus sucursales suspendiendo las facultades de sus directores para la concesión de descuen-

5 Vide Egea Bruno, P. M., La minería cartagenera en torno a la primera guerra mundial..., pág. 7 ; El crac de la minería cartagenera y Coyuntura minera y variables sociométricas..., pág. 167.

6 Vicens-Vives, J., y NAdAl Oller, J., Historia económica de España, Ed. Vicens Vives (6. ed.), Barcelona, 1967, pág. 695.

7 Vide al respecto Bernis, F., Consecuencias económicas de la guerra. Las teorias y la enseñanza de los hechos desde 1914 respecto a: I. El ciclo económlco. II. Producción, distribución, venta y consumo. III. Los precios. IV. Dinero y Bancos, Publ. "Junta de Ampliación de Estudios e Investigaciones Clentificas", Madrid, 1923, pág. 95; Bergamin, F., Influencia de la guerra actual en nuestro desenvolvimiento económico, Est. Tip. Jaime Ratés, Madrid, 1916, pág. 7. Una interesante puesta al día puede contemplarse en RoLDAN, Santiago, y Garcia DelGADO, José Luis, La formación de la sociedad capitalista en España. 1914-1920, CECA, Madrid, 1973, t. II, págs. 183-198. Bibliografía complementaria en EgeA Bruno, P. M., La crisis de 1917 en Cartagena... 
tos $y$ créditos $^{8}$. Por su parte, el Banco de Cartagena se verá igualmente contagiado del pánico financiero. Dejará de pagar los cheques presentados al cobro por cuenta corriente y reducirá el reintegro de fondos impuestos en su caja de ahorros a 50 pesetas semanales, provocando - como es lógico suponer- un formidable atasco en las reservas mercantiles del área ${ }^{9}$.

Dada la especial configuración de nuestra minería, donde la pequeña empresa era la predominante ${ }^{10}$, el conflicto abierto adquiere caracteres irresolubles ${ }^{11}$. Incluso, los grandes capitalistas tropezarán con dificultades insalvables, pues si bien poseian francos o libras no podían, por contra, negociarlas en la plaza ni fuera de ella, viéndose por tanto privados de efectivo.

Hasta mediados de 1915 la Administración no conseguirá del Banco de España la auspiciada ampliación de créditos ${ }^{12}$. Por su parte, la Banca local fue fortaleciendo su encaje y pudo, igualmente, hacer frente a las necesidades de sus imponentes ${ }^{13}$. Sin embargo, nuevas dificultades vinieron a disolver la reacción de las finanzas.

Otro de los efectos provocados por la guerra europea fue la caída de las exportaciones minera, último y casi único objetivo de la producción cartagenera. Las razones hay que buscarlas, de una parte en las sucesivas disposiciones de los gobiernos beli-

8 Vide AJPMM, LRSC, años 1914-1922, fols. 61-62; ACCINC, LA, SE, 6-VIII-1914 (s. f.); Riu, Daniel, Las sucursales del Banco de España, "REH", Madrid, 1916, págs. 291-292, y ANES ALVAREZ, Rafael, «El Banco de España (1874-1914). Un Banco nacional» en La Banca española en la Restauración, vol. I, Servicio de Publicaciones del Banco de España, Madrid, 1974.

9 ACCINC, LA, SE, 12-VIII-1914 (s. f.).

10 Vide Egea Bruno, P. M., La propiedad minera en la sierra de Cartagena, "Anales de la Universidad de Murcia. Facultad de Letras", Murcia, 1984, en prensa.

11 Revista Minera, Metalúrgica y de Ingeniería (Madrid), 16-VIII-1914, pág. 407.

12 Vide IRS, Informes de los inspectores de trabajo sobre la influencia de la guerra en las industrias españolas durante el año 1915, Imp. de la Sucesora de M. Minuesa de los Ríos, Madrid, 1916, pág. 152; vide ítem. BOPM, 9-VIII-1915.

13 Gaceta Minera y Comercial (Cartagena), 2-111-1915, pág. 73. 
gerantes sobre contrabando de guerra, que culminaron con la declaración del bloque submarino ${ }^{14}$.

La industria extractiva y su derivada recibieron un duro golpe. Las páginas de la "Revisa Minera" se hicieron eco de la situación desencadenada: "...Desde que se hizo pública la declaración de bloqueo de las naciones aliadas por el imperio alemán, la oponión señaló en nuetro país, con harto motivo, que la explotación minera española, así como la importación de carbones, estaban llamadas a sufrir hondamente con esta medida, puesto que el carbón viene de Inglaterra y los minerales se exportan principalmente a Inglaterra y Francia, y no hay que pensar en enviar minerales a Francia por tierra...." ${ }^{15}$.

De otra parte, las dificultades ocasionadas por las anteriores disposiciones se dejaron sentir en la disminución del tráfico marítimo ${ }^{16}$. La consecuencia directa no pudo ser otra que el alza extraordinaria de los fletes ${ }^{17}$, y el resultado final fue la inadecuación entre el valor del producto transportado y el precio del transporte. Circunstancias todas ellas que propiciaron la paralización de las demandas.

14 Cfr. Araquistain, Luis, Polémica de la guerra (1914-1915), Ed. Renacimiento, Madrid, 1915, págs. 229-261; Dos ideales políticos y otros trabajos. (En torno a la guerra), Est. Tip. "El Liberal», Madrid, 1916, págs. 279-284. LACOMBA, J. A., La crisis española de 1917, Ed. Clencia Nueva, Madrid, 1970, págs. 25-26.

15 Revista Minera, Metalúrgica y de Ingeniería (Madrid), 24-II-1917, pág. 103.

16 Vide ANDRE, Eloy Luis, La congestión del tráfico y la crisis de los transportes, "REH", Madrid, 1916, págs. 967-970. GaRRIGA Y MASSO, Juan, "Transportes terrestres y martítimos" en El pensamiento catalán ante el conflicto europeo, Imp. Hijos de Domingo Casanova, Barcelona, 1915, págs. 109-185. NavARRETE, Adolfo, El problema maritimo de España, Sociedad Española de Artes Gráficas, Madrid, 1917 y, sin firma, La industria naval española, "BOMM», núm. 16, septiembre, 1918, págs. 59-60.

17 Asociación de NAVIEROS DE BILBAO, Las subsistencias, el transporte de carbones y los fletes, "RMMl», núm. 2487, Madrid, 8-III-1915, págs. 115-118. MADARIAGA, Luis de, Economía y finanzas. El mercado de fletes en 1917. Cotizaciones comparadas desde el comienzo de la guerra, "GMC", núm. 1819, Cartagena, 26-I1-1918, págs. 65-66. 
Otra de las salpicaduras de la guerra que llegó a provocar un grave conflicto en la minería comarcana fue el problema carbonífero. Secularmente la industria española era triburaria del carbón inglés ${ }^{18}$. En los años bélicos, una serie de factores relacionados, sobre todo, con el tráfico marítimo contribuyeron a crear una honda pesadilla a los consumidores de este combustible. Los efectos se podían agrupar en dos grandes niveles. Subida de precios y desabastecimiento ${ }^{19}$. Variables especialmente graves a partir de 1915. En esta fecha, previendo el desastre, se sustituyeron las máquinas de vapor por otras eléctricas. Pero de nada sirvió. La crisis no tardó en extenderse a todo el sector energético. La empresa suministradora se vio igualmente en la imposibilidad de prestar el servicio que le estaba asignado ${ }^{20}$. La situación desencadenada será puesta de relieve por la corporación unionense: "...a consecuencia de la forma defectuosa en que la compañía "Unión Eléctrica de Cartagena" suministra el fluído a las industrias mineras de la región se han paralizado casi todas las minas y fábricas, por cuya causa huelgan infinidad de obreros que hoy se hallan acosados por el hambre y los patronos sufren gravísimos perjuicios...»21.

18 Cfr. Egea Bruno, P. M., Esplendor y miseria.., pág. 215.

19 Vide LAzURTEgul, Julio de, La cuestión de los carbones en España, "GMC", núm. 1697, Cartagena, 26-X-1915, págs. 342-344. PEÑA, Luis de la, Los efectos de la guerra europëa sobre la industria española. El carbón, "GMC", números 1672,1673 y 1676, Cartagena, 4 y 11-V-1915 y 1-VI-1915, pags. 141-144, 149150 y 173-176. MADARIAGA, José María de, La crisis del carbón, "RMMl", número 2621, Madrid, 24-XII-1917, págs. 619-620. COMISION DE ESTUDIO DE LA RIQUEZA HULlERA NACIONAL, Información relativa a la crisis del mercado hullero en España. Medidas propuestas al Gobierno por la Comisión de Estudios para impulsar la producción nacional, Est. Tip. Antonio Marzo, Madrid, 1915, páginas 18-19. GaRCí DelgADO, José Luis, La minería del carbón en España durante la I Guerra Mundial, "Revista de Trabajo», núms. 35-36 (1971), págs. 39-100.

20 Vide AMLU, AC, 17-XI-1918, fol. 218 r. RoLANDI, Bernardino, Informe sobre el problema social-minero en la sierra de Cartagena, Imp. Sobrinos de la Sucesora de M. Minuesa de los Ríos, Madrid, 1924, pág. 18. Pérez SÁnCHEz, Francisco, El problema de la energía eléctrica en la sierra de Cartagena, "GMC», número 1489, Cartagena, 24-lX-1918, pág. 305.

21 AMLU, AC, 17-XI-1918, fol. 218 r. 
Del mismo modo, la escasez de combustible llegó a afectar a la industria metalúrgica, sin que los intentos de sustitución por carbón nacional o por leña diesen los resultados apetecidos $^{22}$.

En este marasmo vino a dislocarse el mercado de metales, al cerrarse Tas Bolsas de Londres y Nueva York, únicos centros de cotización mercantilmente aceptados ${ }^{23}$. En estas circunstancias se desarrollaría un agio sin precedentes ${ }^{24}$ que terminaría con la protectora medida de un precio regulador: "... A que grados llegaria la fiebre de la especulación -escribe entonces un productor cartagenero- ${ }^{25}$ cuando en 1916 las naciones interaliadas tuvieron que fijar y convenir un precio regulador de los metales en Londres que en cuanto al plomo lo fue de 750 pesetas tonelada puerto español...".

Previsión que si en un principio evitó el perpetuo desequilibrio entre la oferta y la demanda, acabaría por convertise en uno de los más graves problemas de la industria local. El considerable deprecio que sufrió la moneda extranjera en el transcurso de la guerra reduciría las 30 libras esterlinas a 600 pesetas, es decir a 150 pesetas por debajo de la par ${ }^{26}$, lo que hacla insostenible el negocio. Las fabulosas demandas de plomo realizadas durante el período bélico sólo sirvieron para enriquecer a los gerentes

22 IRS, Informes de los inspectores de trabajo sobre la influencia de la guerra europea en las industrias españolas (1917-1918), t. III, Imp. Sobrinos de la Sucesora de M. Minuesa de los Ríos, Madrid, 1919, pág. 123.

23 CONSEJo de Mineria, Estadistica minera de España. Año 1914..., pág. 21. Rubio, Juan, Los minerales de plomo en Cartagena y las tarifas de precios, «RMMl», núm. 2689, Madrid, 24-V-1919, págs. 251-252.

24 Cegarra Salcedo, la Unión, ciudad minera. Causas productoras de la crisis de su industria y medios que pudieran adoptarse para solucionarla, Ed. Levante, Cartagena, 1920, pág. 25.

25 Revista Minera y Metalúrgica (Cartagena), 25-VIII-1920, pág. 557.

26 Sin firma, El problema del cambio en España, Imp. «Las Finanzas», Madrid, 1929, págs. 56-58. 
extranjeros de la especulación ${ }^{27}$. El absoluto control del mercado de metales - desde la fijación de los precios a la demanda generalizada- decidirá, por el contrario, la ruina de los industriales comarcanos ${ }^{28}$.

La terminación de la guerra no supondrá, como cabía esperar, el relanzamiento económico del área. Antes al contrario. Ahora se habían dado cita un cúmulo de factores negativos. Desde el agotamiento de los criaderos a la caída de los precios ${ }^{29}$.

Con semejente predisposición llegó el crítico año 1921, uno de los más aciagos de la economía mundial ${ }^{30}$. Coyuntura que terminará for romper el precario equilibrio de nuestra industria. El cierre de labores fue completo ${ }^{31}$. A partir de entonces la minería de Cartagena arrastrará una languidez agónica ${ }^{32}$. Su mera subsistencia precisará de apuntalamientos. En 1928 se

27 Sin firma, Los negocios del plomo en España, "RMM», Cartagena, 25-IV-1923, págs. 953-954.

28 Cfr. Egea Bauno, P. M., La mineria cartagenera en torno a la primera Guerra Mundial, págs. 46-50.

29 Vide Consejo de Mineria, Estadística minera de España. Año 1919, Madrid, 1920, pág. 284. GUARDIOLA, Ricardo, La minería de Cartagena, elemento importante de la riqueza nacional, necesita el auxilio del Estado, "BOMM", núm. 30, noviembre, 1919, págs. 45-46; La crisis plomera, "BOMM", núm. 22, marzo, 1919, págs. 66-69. Pérez SÁnChez, F., La baja del plomo, "GMC", núm. 1871, Cartagena, 25-II-1919, pág. 57. Sin firma, Crisis de las minas metalíferas, "BOMM", núm. 25, junio, 1919, págs. 47-49. BENTABOL, Horacio, Memoria de la visita girada a los distritos de la quinta región, "BOMM", núms. 21 y 22, febrero y marzo de 1919 , págs. 49-61 y $27-40$.

30 Alvarez Mendiluce, E., Impresión general de la marcha económica de la minería y de la metalurgia en el año 1921, "RMMl», núm. 2816, Madrid, 16-I-1922, páginas 37-38.

31 IRS, Crisis industrial fuera de las capitales de provincia. Resumen de los informes remitidos por los inspectores de trabajo en agosto-septiembre de 1921 , Imp. SQbrinos de la Sucesora de M. Minuesa de los Ríos, Madrid, 1922, página 5.

32 Contreras, José, La minería del plomo en España, «RMMl", núm. 2865, Madrid, 24-1-1923, págs. 41-42. 


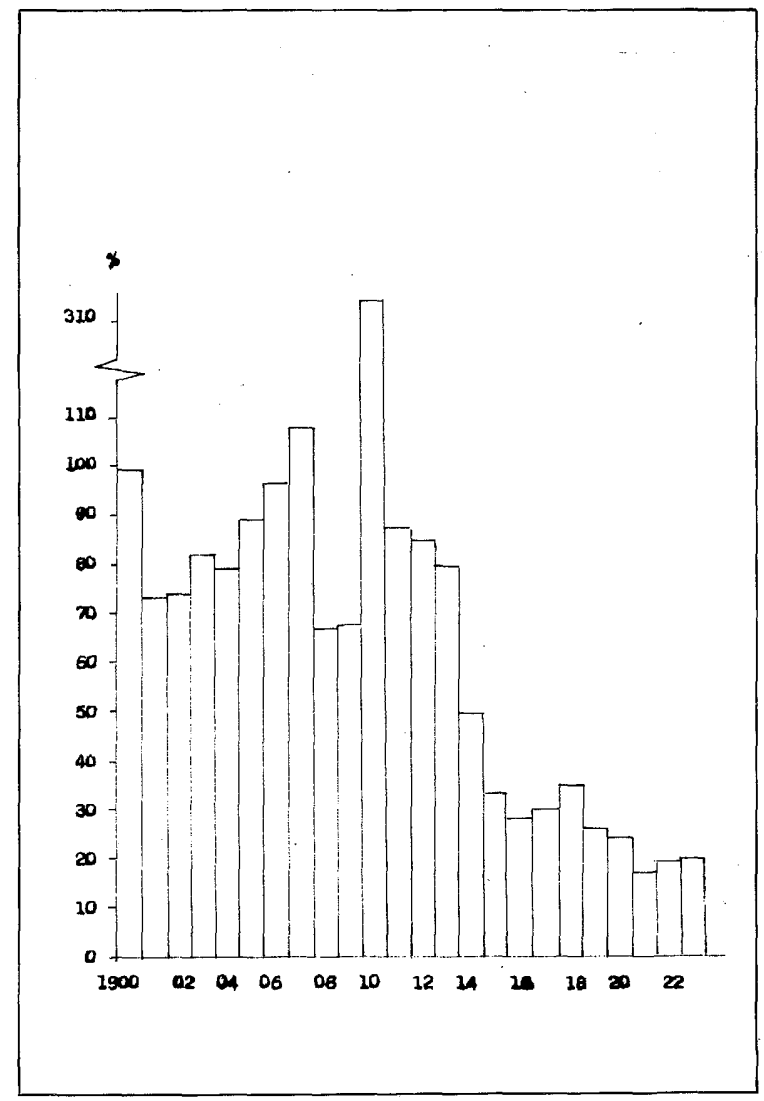

GRAFICO 1: Producción minero-metalúrgica del distrito murciano (1900-1923) 


\section{TABLA I}

RELACION ABSOLUTA Y PORCENTUAL ENTRE LA PRODUCCION MINERA Y LA EVOLUCION DEMOGRAFICA DE LA SIERRA CARTAGENERA (1900-1923)

\begin{tabular}{rrrrrrrr}
\hline \multirow{2}{*}{ Años } & \multicolumn{2}{c}{ F. MINERO-METALUR. } & \multicolumn{2}{c}{ CARTAGENA } & \multicolumn{2}{c}{ LA UNION } \\
& \multicolumn{1}{c}{ T.M. } & \multicolumn{1}{c}{$\%$} & HABIT. & \multicolumn{1}{c}{$\%$} & HABIT. & \multicolumn{1}{c}{$\%$} \\
\hline 1900 & 1.209 .580 & 100,00 & 99.871 & 100,00 & 30.275 & 100,00 \\
1901 & 883.508 & 73,04 & 100.135 & 100,26 & 30.272 & 99,99 \\
1902 & 896.375 & 74,11 & 100.399 & 100,53 & 30.269 & 99,98 \\
1903 & 997.745 & 82,49 & 100.665 & 100,80 & 30.266 & 99,97 \\
1904 & 960.063 & 79,37 & 100.931 & 101,06 & 30.264 & 99,96 \\
1905 & 1.079 .740 & 89,26 & 101.197 & 101,33 & 30.261 & 99,95 \\
1906 & 1.170 .024 & 96,73 & 101.465 & 101,60 & 30.258 & 99,94 \\
1907 & 1.306 .782 & 108,03 & 101.733 & 101,86 & 30.255 & 99,93 \\
1908 & 810.684 & 67,02 & 102.002 & 102,13 & 30.253 & 99,92 \\
1909 & 814.067 & 67,30 & 102.272 & 102,40 & 30.251 & 99,92 \\
1910 & 3.800 .335 & 314,18 & 102.542 & 102,67 & 30.249 & 99,91 \\
1911 & 1.053 .410 & 87,09 & 101.962 & 102,09 & 29.658 & 97,96 \\
1912 & 1.031 .596 & 85,28 & 101.386 & 101,52 & 29.080 & 96,05 \\
1913 & 963.657 & 79,67 & 100.813 & 100,94 & 28.512 & 94,17 \\
1914 & 600.974 & 49,68 & 100.243 & 100,37 & 27.955 & 92,34 \\
1015 & 398.025 & 32,90 & 99.676 & 99,80 & 27.410 & 90,54 \\
1916 & 339.571 & 28,07 & 99.113 & 99,24 & 26.875 & 88,77 \\
1917 & 363.896 & 30,08 & 98.552 & 98,68 & 26.350 & 87,03 \\
1918 & 431.955 & 35,71 & 97.995 & 98,12 & 25.836 & 85,34 \\
1919 & 318.424 & 26,32 & 97.441 & 97,57 & 25.331 & 83,67 \\
1920 & 295.283 & 24,41 & 96.891 & 97,02 & 24.837 & 82,04 \\
1921 & 215.045 & 17,78 & 97.440 & 97,56 & 21.896 & 72,32 \\
1922 & 236.117 & 19,52 & 97.991 & 98,12 & 19.303 & 63,76 \\
1923 & 240.494 & 19,88 & 98.546 & 98,67 & 16.966 & 56,04 \\
\hline
\end{tabular}

Fuente: Elaborado a partir de Estadística(s) minera(s) de España. Años 1900 1923 e INE: Poblaciones calculadas referidas a $10^{\circ}$ de julio y 31 de diciembre a partir del censo del año 1900. Imp. Ramírez, Madrid, 1958, 47 páginas. 
crea el consorcio del plomo ${ }^{33}$. Un año antes el sindicato para el desagüe de las minas del Beal fue reforzado con unas reales órdenes por las cuales el Estado se incautaba de sus instalaciones ${ }^{34}$. Y, por las mismas fechas, se formó el sindicato minero de Cartagena-Mazarrón. Con estas coordenadas el perfil de la producción sólo pudo ser decreciente. (Vide gráfico I);

El marco económico descrito, como veremos a continuación, remodelará la estructura demográfica de la sierra cartagenera. La crisis minera desencadenada alterará profundamente no sólo el crecimiento potencial, sino también la distribución de los efectivos poblacionales en sus diversos niveles de análisis. La relación entre sendas variables puede contemplarse en la tabla I.

Hasta 1910 la producción minero-metalúrgica se sostuvo con levísimas variaciones. Su precipitado demográfico fue un fiel reflejo de esta evolución. Pequeñas alzas en Cartagena y mínimas pérdidas en La Unión.

A partir de la fecha apuntada la declinación económica y la inflexión demográfica marcharán juntas. La recesión de los efectivos poblacionales será mucho más acusada en La Unión que en Cartagena. La ciudad departamental, con una mayor diversificación de la oferta laboral, pudo absorver la demanda de los mineros desempleados.

33 González llana, E., el plomo en España, DGMC, Madrid, 1949, pág. 37.

${ }^{34}$ SDMB, Memoria historial del año 1927. Imp. B. Jiménez. Cartagena. 1928, ps. $4-5$. 


\section{RITMOS DE CRECIMIENTO}

Constataremos, en primer lugar, el balance cuantitativo global:

\section{TABLA II}

\section{EVOLUCION DEMOGRAFICA DE CARTAGENA Y LA UNION COMPARADA CON LA PROVINCIA DE MURCIA $Y$ EL TOTAL NACIONAL (1900-1924) \\ (Año base $1900=100$ )}

\begin{tabular}{rrrrrrrrrr}
\hline \multirow{2}{*}{ AÑOS } & \multicolumn{2}{c}{ CARTAGENA } & \multicolumn{2}{c}{ LA UNION } & \multicolumn{2}{c}{ P. MURCIA } & \multicolumn{2}{c}{ NACIONAL } \\
& P. Hecho & $\%$ & P.Hecho & $\%$ & P. Hecho & $\%$ & P. Hecho & $\%$ \\
\hline 1900 & 99.871 & 100,00 & 30.275 & 100,00 & 577.987 & 100,00 & 18.607 .674 & 100,00 \\
1910 & 102.542 & 102,67 & 30.249 & 99,91 & 615.105 & 106,09 & 19.927 .150 & 107,09 \\
1920 & 96.891 & 97,01 & 24.837 & 82,03 & 638.639 & 110,49 & 21.303 .162 & 114,48 \\
1924 & 99.104 & 99,23 & 15.002 & 49,55 & 641.352 & 110,96 & 22.160 .200 & 119,09 \\
\hline
\end{tabular}

Fuente: Elaboración propia a partir de los censós de población y de INE, Pobiaciones calculadas referidas a $10^{\circ}$ de julio y 31 de diciembre a partir del censo del año 1900, Imp. Ramírez, Madrid, 1958, 47 págs.

La tendencia de crecimiento observada por la población nacional y murciana no es seguida por Cartagena y mucho menos por La Unión, cuya población de hecho experimenta un claro descenso. 
Una vez establecidas las líneas de evolución demográfica, nos interesa conocer sus ritmos de crecimiento, tanto anuales como semestrales. Para el cálculo de las cifras referentes a los años de los períodos intercensales utilizaremos la interpolación, considerando los dos censos extremos como términos de una progresión geométrica. Por tanto, siendo $\mathbf{P}_{1}$ y $\mathbf{P}_{2}$ los resultados de dos censos sucesivos separados entre sí por veinte semestres, la población para el semestre iésimo será $P_{i}: P_{1}\left(P_{2} / P_{1}\right)^{1 / 20}$. A partir de los resultados elaborados así, hemos obtenido los siguientes datos:

TABLA III

EVOLUCION DE LOS RITMOS DE CRECIMIENTO

(1901-1924)

\begin{tabular}{lrrrrrrrrr}
\hline \multirow{2}{*}{ PERIOdOS } & \multicolumn{2}{c}{ CARTAGENA } & \multicolumn{2}{c}{ LA UNION } & \multicolumn{2}{c}{ P. MURCIA } & \multicolumn{2}{c}{ NACIONAL } \\
& Semestr. & Anual & Semestr. & Anual & Semestr. & Anual & Semestr. & Anual \\
\hline $1901-1910$ & 0,13 & 0,26 & $-0,005$ & $-0,01$ & 0,31 & 0,62 & 0,34 & 0,68 \\
$1901-1910$ & $-0,29$ & $-0,58$ & $-0,97$ & $-1,94$ & 0,20 & 0,40 & 0,48 & 0,96 \\
$1901-1910$ & 0,27 & 0,54 & $-2,62$ & $-5,24$ & 0,06 & 0,12 & 0,50 & 1,00 \\
\hline
\end{tabular}

Fuente: Elaboración propia a partir de INE: op. cit.

Solamente la población nacional conocerá un ritmo en constante crecimiento. La provincia de Murcia, aunque con parámetros positivos, experimentará un sensible retroceso. Cartagen, por su parte, tras la importante inflexión de los años 19111920 volverá a recuperar y aun superar las tasas de crecimiento iniciales. Finalmente, La Unión detentará durante todo el período el signo negativo. La decadencia económica del núcleo minero gravitará pesadamente sobre el factor humano. Al final del ciclo ni siquiera conservará el cincuenta por ciento de los efectivos poblacionales del año base.

La cuantificación de los retrocesos, tanto en Cartagena como en La Unión, quedan avaladas en la siguiente tabla: 


\section{VARIACIONES EN LA POBLACION \\ DURANTE LOS PERIODOS 1901-1910 Y 1911-1920}

\begin{tabular}{lrrrr}
\hline MUNICIPIOS & \multicolumn{4}{c}{ POR 100 ABSOLUTO } \\
& $1901-1910$ & $1911-1920$ & $1901-1910$ & $1911-1920$ \\
\hline Cartagena & 2.671 & -5.651 & 2,67 & $-5,51$ \\
La Unión & -26 & -5.412 & $-0,09$ & $-17,89$ \\
\hline
\end{tabular}

Fuente: Elaborado a partir de DGE: Censo de la población de España según el empadronamiento hecho en la península e islas adyacentes el 31 de diciembre de 1920, Imp. de M. G. Fernández, Madrid, 1922, tomo I, página XXXIII.

El progresivo deterioro de las estructuras demográficas locales quedará de relieve al relacionarlo con los valores nacionales. Si en el primer ciclo afecta tan sólo a La Unión, que se emplaza en el onzavo lugar de los municipios de 20.000 y más habitantes que presentan los mínimos incrementos por 100 habitantes, en el periodo 1911-1920 Cartagena ya se instala en el quinto lugar y La Unión en el segundo, inmediatamente detrás de Cuevas de Vera, otra entidad minera afectada por la crisis de sus bases económicas ${ }^{35}$.

La tasa media anual de crecimiento fue en consecuencia negativa en ambos perfodos para La Unión y sólo ocurrió así en el caso de Cartagena para el último ciclo.

35 DGE, Censo de la población de España según el empadronamiento hecho en la península e islas adyacentes el 31 de diciembre de 1920..., T. I, pág. XXXV. 


\section{TASA MEDIA ANUAL DE CRECIMIENTOO \\ (\%) DE 1900 A 1920}

\begin{tabular}{lrr}
\hline MUNICIPIO & $1900-1910$ & $1910-1920$ \\
\hline Cartagena & 0,27 & $-0,55$ \\
La Unión & $-0,01$ & $-1,79$ \\
\hline
\end{tabular}

Fuente: Elaborado a partir de DIEZ NICOLAS, Juan, Tamaño, densidad y crecimiento de la población de España. 1900-1960, CSIC, Instituto Balmes de Sociología, Madrid, 1971, págs. 47-65.

Finalmente, el crítico proceso quedará configurado por la contracción de la densidad. Frente al avance constante de los valores provinciales y nacionales, Cartagena y La Unión verán disminuir sus habitantes por kilómetro cuadrado. Aún asi, sus parámetros se mantendrán muy por encima de las medias murcianas y españolas.

\section{TABLA VI}

EVOLUCION DE LA DENSIDAD (HAB./KM²) EN CARTAGENA Y LA UNION COMPARADA CON LA DE LA PROVINCIA DE MURCIA Y LA NACIONAL (1900-1920)

\begin{tabular}{lrrr}
\hline & \multicolumn{1}{c}{1900} & \multicolumn{1}{c}{1910} & \multicolumn{1}{c}{1920} \\
\hline Cartagena & 179.00 & 184,00 & 174,00 \\
La Unión & $1.211,00$ & $1.210,00$ & 993,00 \\
P. Murcia & 51,07 & 54,35 & 54,43 \\
España & 36,84 & 39,49 & 42,24 \\
\hline
\end{tabular}

Fuente: Elaborado a partir de Diez Nicolas, Juan, op. cit., págs. 47-65; y DGE, op. cit., pág. LXXXVIII. 


\section{DISTRIBUCION DE LA POBLACION}

Una vez constatado el retroceso demográfico, nos interesa conocer las características que revistió el fenómeno y á qué entidades de población afectó. Para ello examinaremos en primer lugar la distribución de la población cartagenera.

El mayor peso específico viene dado por las diputaciones rurales que, como veremos más adelante, actuarán de barómetro de las presiones demográficas de la zona. Cuantificando las variables que representan las poblaciones de las distintas entidades obtendremos la tipificación del hinterland cartagenero.

\section{TABLA VII}

INTEGRACION URBANA DE LA POBLACION CARTAGENERA (1900-1920)

\begin{tabular}{lcccccc}
\hline \multirow{2}{*}{ TIPIFICACION } & \multicolumn{2}{c}{1900} & \multicolumn{2}{c}{1910} & \multicolumn{2}{c}{1920} \\
& TOTALES & $\%$ & TOTALES & $\%$ & TOTALES & $\%$ \\
\hline Ciudad & 41.315 & 41,36 & 35.386 & 34,50 & 33.444 & 34,51 \\
Barrios & 14.332 & 14,35 & 14.125 & 13,77 & 15.334 & 15,82 \\
D. Rurales & 44.224 & 44,28 & 53.031 & 51,71 & 47.913 & 49,45 \\
\hline
\end{tabular}

Fuente: DGIGE y DGE, Nomenclator de las ciudades, villas, lugares y demás entidades de población. Años correspondientes.

La pérdida de efectivos poblacionales afectó en primera instancia y de forma espectacular a la ciudad. A pesar de registrarse en 1910 un incremento demográfico sobre 1900 para el total de la población, aquélla ya acusa un retroceso de cerca de 15 puntos, tendencia que se confirmará en 1920.

Los barrios extramuros sufrirán también en 1910 un retroceso, si bien muy leve, apenas dos puntos, para recuperarse al final del período con un saldo positivo. Las diputaciones rurales ofrecen una clara preeminencia durante todo el ciclo, especial- 
mente significativa para 1910, lo que hace pensar en un replio. gue de la zona urbana a la rural. En 1920, ante la inflexión general, su crecimiento quedará frenado.

TABLA VIII

CRECIMIENTO PORCENTUAL DE LA POBLACION DE CARTAGENA

(1900-1920)

\begin{tabular}{lrrrrrrr}
\hline \multirow{2}{*}{ TIPIFICACION } & \multicolumn{2}{c}{1900} & \multicolumn{2}{c}{1910} & \multicolumn{2}{c}{1920} \\
& TOTALES & N. I. & TOTALES & N. I. & TOTALES & N. I. \\
\hline Ciudad & 41.315 & 100,00 & 35.386 & 85,64 & 33.444 & 80,94 \\
Barrios & 14.332 & 100,00 & 14.125 & 98,55 & 15.534 & 108,38 \\
D. Rurales & 44.224 & 100,00 & 53.031 & 119,91 & 47.913 & 108,34 \\
\hline
\end{tabular}

Fuente: DGIGE, Nomenclator de las ciudades...

Los diferentes ritmos de crecimiento a que estuvieron sometidas cada una de las entidades que componían la población cartagenera pueden seguirse en la tabla IX:

Si reagrupamos estas variables bajo los conceptos de máximos y mínimos (vide tablas $\mathrm{X}$ y XI), observaremos que durante el período 1901-1910 los mayores incrementos se producen en las diputaciones rurales que son exclusivamente agrícolas. En el ciclo 1911-1920 se unirán a estas constantes los barrios de Santa Lucía, San Antonio Abad y Peral, este último también con fuerte incremento en la etapa precedente. De otro lado, destaca el hecho significativo de que los ritmos de crecimiento son mucho más cortos en el segundo ciclo que en el primero. 


\title{
TABLA IX
}

\author{
RITMOS DE CRECIMIENTO \\ DE LAS ENTIDADES CARTAGENERAS \\ (1901-1920)
}

\begin{tabular}{|c|c|c|c|c|c|}
\hline \multirow{2}{*}{$\begin{array}{l}\text { TIPITICACION } \\
\text { ENTIDADES }\end{array}$} & \multirow{2}{*}{$\begin{array}{l}\text { NOMBRE DE } \\
\text { LA ENTIDAD }\end{array}$} & \multicolumn{2}{|c|}{ ABSOLUTO } & \multicolumn{2}{|c|}{ POR 100} \\
\hline & & $1901-10$ & $1911-20$ & $1901-10$ & $1911-20$ \\
\hline Ciudad ........... & Cartagena & -5.929 & -1.942 & $-14,35$ & $-5,40$ \\
\hline \multirow[t]{2}{*}{$\begin{array}{l}\text { Barrios } \\
\text { Extramuros }\end{array}$} & $\begin{array}{l}\text { S. Ant. Abad } \\
\text { Santa Lucía } \\
\text { Concepción } \\
\text { Peral }\end{array}$ & $\begin{array}{r}-223 \\
876 \\
223 \\
669\end{array}$ & $\begin{array}{r}404 \\
1.120 \\
-307 \\
192\end{array}$ & $\begin{array}{r}-5,60 \\
-14,95 \\
9,38 \\
31,05\end{array}$ & $\begin{array}{r}10,85 \\
22,48 \\
-11,81 \\
6,80\end{array}$ \\
\hline & $\begin{array}{l}\text { Albujón } \\
\text { Algar } \\
\text { Aljorra } \\
\text { Alumbres } \\
\text { Beal } \\
\text { Campo Nubla } \\
\text { Canteras } \\
\text { Escombreras } \\
\text { Hondón }\end{array}$ & $\begin{array}{r}-408 \\
871 \\
951 \\
100 \\
770 \\
-181 \\
-635 \\
6 \\
117\end{array}$ & $\begin{array}{r}179 \\
-1.345 \\
-810 \\
290 \\
-1.440 \\
268 \\
160 \\
68 \\
215\end{array}$ & $\begin{array}{r}-28,47 \\
18,53 \\
65,22 \\
2,66 \\
11,30 \\
-14,60 \\
-32,20 \\
0,50 \\
12,02\end{array}$ & $\begin{array}{r}17,46 \\
-24,14 \\
-33,62 \\
7,49 \\
-18,99 \\
25,33 \\
11,96 \\
5,63 \\
19,72\end{array}$ \\
\hline Dipt & $\mathrm{LaPa}$ & 730 & -1.352 & 34,01 & $-47,00$ \\
\hline \multirow[t]{10}{*}{ Rurales......... } & Lentíscar & -37 & 203 & $-2,60$ & 15,01 \\
\hline & $\begin{array}{l}\text { Magd } \\
\text { Médic }\end{array}$ & $\begin{array}{l}900 \\
131\end{array}$ & $\begin{array}{r}67 \\
-18\end{array}$ & $\begin{array}{l}38,99 \\
35,50\end{array}$ & $\begin{array}{r}21,10 \\
-37,20\end{array}$ \\
\hline & Mira & 10 & - & & $-1,57$ \\
\hline & Perín & 76 & -1.11 & 24 & $-29,05$ \\
\hline & Plan & & 2 & 28 & 7,35 \\
\hline & 80 & & & & \\
\hline & Puertos & 1.03 & -51 & 76,09 & $-21,44$ \\
\hline & & & & & 40 , \\
\hline & & & 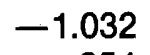 & & $-5 \xi$ \\
\hline & & & & 7 & \\
\hline
\end{tabular}

Fuente: DGIGE y DGE, Nomenclator de las ciudades... 
En cuanto a los mínimos, se decanta como fenómeno puramente urbano e industrial. En 1901-1910 afectará a Santa Lucía, Cartagena, San Antonio Abad, Concepción y a las entidades mineras de Escombreras, Alumbres, Beal y Rincón. En 1911-1910 los parámetros de la regresión son mucho más abultados, ampliándose ésta a algunas entidades agrícolas.

Entre una y otra constante se da cierto efecto compensador, de manera que el ciclo 1901-1910 se integra con importantes máximos y mínimos pequeños, ocurriendo justamente lo contrario en el segundo período: cortas subidas y violentos descensos. Ello nos hace pensar en que la línea de ruptura de la evolución demográfica de Cartagena se sitúa exactamente a partir de 1911, coincidiendo con la regresión económica.

\section{TABLA X}

ENTIDADES DE POBLACION QUE PRESENTAN LOS MAXIMOS INCREMENTOS POR 100 HABITANTES (1901-1920)

\begin{tabular}{lclc}
\hline ENTIDADES & $1901-1910$ & ENTIDADES & $1911-1920$ \\
\hline Puertos & 76,09 & Rincón & 40,45 \\
San Félix & 71,30 & Campo Nubla & 25,33 \\
Santa Ana & 68,73 & Santa Lucla & 22,48 \\
Aljorra & 65,22 & Magdalena & 21,10 \\
Pozo-Estrecho & 56,23 & Hondón & 19,72 \\
Magdalena & 38,99 & Albujón & 17,46 \\
Médicos & 35,50 & Lentíscar & 15,01 \\
La Palma & 34,01 & Canteras & 11,96 \\
Peral & 31,05 & San Antonio Abad & 10,85 \\
Plan & 28,07 & Alumbres & 7,49 \\
Perín & 24,78 & Plan & 7,35 \\
Algar & 18,53 & Peral & 6,80 \\
Miranda & 15,20 & Escombreras & 5,63 \\
\hline
\end{tabular}

Fuente: DGIGE y DGE, Nomenclator de las ciudades... 
ENTIDADES DE POBLACION QUE PRESENTAN LOS MINIMOS INCREMENTOS POR 100 HABITANTES (1901-1920)

\begin{tabular}{lrll}
\hline ENTIDADES & $1901-1902$ & ENTIDADES & $1911-1920$ \\
\hline Canteras & $-32,20$ & Sanita Ana & $-55,90$ \\
Albujón & $-28,47$ & La Palma & $-47,00$ \\
Santa Lucía & $-14,95$ & Médicos & $-37,20$ \\
Campo Nubla & $-14,60$ & San Félix & $-36,59$ \\
Cartagena & $-14,35$ & Aljorra & $-33,62$ \\
San Antonio Abad & $-5,60$ & Perín & $-29,05$ \\
Lentíscar & $-2,60$ & Algar & $-24,14$ \\
Escombreras & 0,50 & Puertos & $-21,44$ \\
Alumbres & 2,65 & Beal & $-18,99$ \\
Concepción & 9,38 & Concepción & $-11,81$ \\
Beal & 11,30 & Pozo-Estrecho & $-6,38$ \\
Hondón & 12,02 & Cartagena & $-5,40$ \\
Rincón & 12,18 & Miranda & $-1,57$ \\
\hline
\end{tabular}

Fuente: DGIGE y DGE, Nomenclator de las ciudades...

En resumen, y como hemos apuntado, las pérdidas más importantes se producen en 1911-1920, pero los núcleos urbanos se verán afectados sobre todo en 1901-1910. De manera que en esta primera etapa las diputaciones rurales absorberán, en parte, las fugas de la ciudad y de los barrios extramuros. Compensación que no se producirá en el segundo ciclo, pues el incremento de los barrios es insuficiente para equilibrar la recesión producida en la ciudad y en los núcleos rurales. El proceso demográfico era ya irreversible. Una y otra peculiaridad del fenómeno - compensación y desequilibrio- pueden constatarse en la siguiente tabla: 


\section{TABLA XII}

VARIACIONES EN LOS RITMOS DE CRECIMIENTO DE LA POBLACION DE CARTAGENA (1901-1920)

\begin{tabular}{lrrrr}
\hline \multirow{2}{*}{ TIPIFICACION } & \multicolumn{2}{c}{ ABSOLUTO } & \multicolumn{2}{c}{ POR 100} \\
& $1901-1910$ & $1911-1920$ & $1901-1910$ & $1911-1920$ \\
\hline Ciudad & -5.929 & -1.942 & $-14,35$ & $-5,40$ \\
B. Extramuros & -207 & -1.409 & $-1,40$ & 9,90 \\
D. Rurales & 8.807 & -5.118 & 19,91 & $-9,60$ \\
\hline \multicolumn{1}{c}{ TOTALES } & 2.671 & -5.651 & 2,67 & $-5,50$ \\
\hline
\end{tabular}

Fuente: DGIGE y DGE, Nomenclator de las ciudades...

Por su parte, la evolución de La Unión estuvo sometida a las variaciones siguientes:

TABLA XIII

CRECIMIENTO PORCENTUAL DE LA POBLACION DE LA UNION (1900-1920)

\begin{tabular}{llrrrrrrr}
\hline TIPIFICACION & \multirow{2}{*}{ NOMBRE } & \multicolumn{2}{c}{1900} & \multicolumn{2}{c}{1910} & \multicolumn{2}{c}{1920} \\
ENTIDADES & ENTIDAD & TOTALES & N. IND. & TOTALES & N. IND. & TOTALES & N. IND. \\
\hline Ciudad & La Unión & 22.342 & 100,00 & 20.185 & 90,34 & 17.257 & 77,24 \\
Diputación & Portman & 894 & 100,00 & 2.293 & 256,48 & 1.895 & $2.11,96$ \\
Diputación & Roche & 502 & 100,00 & 565 & 112,50 & 403 & 80,27 \\
Caseríos & - & 6.537 & 100,00 & 7.206 & 110,23 & 5.282 & 80,80 \\
\hline
\end{tabular}

Fuente: Elaborado a partir de DGIGE y DGE, Nomenclator..., ańos 1900, 1910 y 1920.

Desde 1910 la ciudad de La Unión acusa pérdidas en su población, confirmándose tal regresión en 1920. Destaca igualmente el alza espectacular de la diputación de Portman. Aunque también positivas, las evoluciones de Roche y caserios dispe-ı 
ros, presentan una progresión mucho más reducida. En 192.0, a excepción de Portman, las restantes entidades de población pierden efectivos, en particular la puebla minera. Los ritmos de crecimiento quedan establecidos de la siguiente manera:

\section{TABLA XIV}

VARIACIONES EN LA POBLACION DE LA UNION (1901-1920)

\begin{tabular}{lrrrr}
\hline \multirow{2}{*}{ ENTIDADES } & \multicolumn{2}{c}{ INCREMENTO ABSOLUTO } & \multicolumn{2}{c}{ INCREMENTO POR 100 } \\
& $1901-1910$ & $1911-1920$ & $1901-1910$ & $1911-1920$ \\
\hline Portman & 1.399 & -398 & 156,48 & $-17,35$ \\
Roche & 63 & -162 & 12,54 & $-28,67$ \\
La Unión & -2.157 & -2.928 & $-9,65$ & $-14,50$ \\
Caseríos & 669 & -1.924 & 10,23 & $-26,69$ \\
\hline
\end{tabular}

Fuente: Elaborado a partir de la tabla XIV.

En el período 1911-1920, cuando la crisis económica de la sierra minera ha alcanzado cotas angustiosas 36 , se asiste a una regresión generalizada.

\section{CAMBIOS EN LA COMPOSICION POR EDAD Y SEXO}

Los parámetros utilizados a continuación han sido corregidos teniendo en cuenta los grupos de edades. Los censos (fuente básica) no seguían una distribución equitativa en estas. Igualmente, es preciso señalar que se han incluido los "no consta", haciendo una redistribución de las variables de acuerdo con la formula FM = NCIPT - NC, en la que FM es el factor multiplicador, NC los «no consta» y PT la población total correspondiente

${ }^{36}$ Egea Bruno, P. M., La minerla cartagenerá en torno a la Primera Guerra Mundial..., ps. 5-75 
a un sexo y aplicando la variable resultante a la serie de los grupos de edades declaradas.

En 1900 había en Cartagena 50.898 hombres y 48.973 mujeres, 1.925 más de aquéllos que de éstas. Con ello là tasa de mas. culinidad se situaba en 1,03. Tal valor sólo resulta explicable por una fuerte inmigración. Por grupos de edad, la tasa ofrece las siguientes características:

\section{TABLA XV}

TASA DE MASCULINIDAD POB EDADES EN CARTAGENA (1900-1920)

\begin{tabular}{cccc}
\hline GRUPOS DE EDAD & 1900 & 1910 & 1920 \\
\hline $0-4$ & 0,97 & 1,04 & 1,08 \\
$5-9$ & 1,04 & 0,97 & 1,05 \\
$10-14$ & 1,03 & 0,95 & 0,98 \\
$15-19$ & 0,90 & 0,98 & 0,90 \\
$20-24$ & 1,37 & 1,22 & 1,31 \\
$25-29$ & 1,11 & 1,02 & 1,01 \\
$30-34$ & 1,02 & 1,00 & 1,02 \\
$35-39$ & 0,98 & 0,94 & 0,93 \\
$40-44$ & 1,07 & 0,99 & 0,94 \\
$45-49$ & 1,00 & 1,00 & 0,95 \\
$50-54$ & 0,97 & 0,95 & 0,96 \\
$55-59$ & 0,98 & 0,93 & 0,93 \\
$60-64$ & 0,94 & 0,96 & 0,91 \\
$65-69$ & 0,92 & 0,98 & 0,91 \\
$70-74$ & 0,89 & 0,89 & 0,89 \\
$75-79$ & 0,87 & 0,84 & 0,88 \\
$80-84$ & 0,78 & 0,81 & 0,90 \\
$85-89$ & 0,67 & 0,77 & 0,93 \\
$90-94$ & 0,61 & 0,85 & 0,80 \\
$95-99$ & 0,46 & 1,00 & 0,53 \\
Más de 100 & 1,20 & 1,00 & - \\
\hline
\end{tabular}

Fuente: Elaborado a partir de DGIGE y DGE: Censos de población, anos 1900-1920. 
Las diferencias se acentúan precisamente en aquellas cohortes comprendidas en los estratos propiamente migratorios: de 20 a 30 años. Las restantes variables -igualmente superiores a la media "natural» - tienen su razón de ser en las sucesivas oleadas migratorias que tipificaron el ciclo demográfico reciente de Cartagena, foco de atracción laboral desde que la cuenca resucitó en 1840 su pasado minero ${ }^{37}$.

Parecida integración ofrecen las variaciones de la tasa de masculinidad en 1910: 1,004, si bien la relación de dependencia se ha reducido un tanto, cuando el inicio de la crisis económica que afectó a la zona paralizó a posibles inmigrantes.

Por lo que respecta a 1920, la relación queda en 1,01, superando a la tasa del decenio precedente, pero por debajo del inicio de la centuria, siendo también las edades de 20 a 34 años las que presentan una hinchazón atípica.

En resumen, durante todo el período la tasa de masculinidad sufrirá la superposición, y en cierto modo la desfiguración, del efecto de "generación" sobre el de la "edad". Si la tendencia general de la medida de la "sex ratio" es el de crecimiento paulatino, aquí se verá enmascarada por el efecto de "generación".

En La Unión, la tasa de masculinidad ofrece una progresiva caída. Pasa de 1,01 en 1900 a 0,99 en 1910 y a 0,83 en 1920. Las razones hay que buscarlas - una vez más - en las intrínsecas relaciones entre el proceso demográfico y las coyunturas económicas. La ciudad minera sufrirá en carne propia las violentas oscilaciones que experimentaron los minados. Desde 1894 la sierra entraría en una profunda depresión ${ }^{38}$, que tras la recuperación -más aparente que real- en el primer quinquenio del nuevo siglo, se convertiría en definitiva a partir de 1914, cuando la guerra europea provoque el cierre de mercados ${ }^{39}$.

37 Egea Bruno, P. M., El resurgir contemporáneo de la sierra cartagenera..., ps. 99-105.

38 VARGAS, Julio de, Viaje por España. Alicante-Murcia. Tip. "El Liberal». Madrid. 1895 , ps. $252-265$.

39 Crf. Egea Bruno, P. M., La minería cartagenera en torno a la Primera Guerra Mundial..., ps. 9-33. 
La evolución referida a los diferentes grupos de edad ofrece claramente marcadas estas circunstancias, como puede observarse en la tabla siguiente:

TABLA XVI

TASAS DE MASCULINIDAD EN LA UNION (1900-1920)

\begin{tabular}{cccc}
\hline GRUPOS DE EDAD & 1900 & 1910 & 1920 \\
\hline $0-4$ & 1,07 & 1,07 & 1,01 \\
$5-9$ & 1,07 & 1,01 & 0,87 \\
$10-14$ & 1,04 & 1,00 & 0,69 \\
$15-19$ & 0,95 & 1,02 & 0,67 \\
$20-24$ & 0,98 & 0,98 & 0,70 \\
$25-29$ & 0,99 & 1,01 & 0,91 \\
$30-34$ & 1,07 & 1,02 & 0,86 \\
$35-39$ & 1,06 & 0,96 & 0,93 \\
$40-44$ & 1,12 & 0,99 & 0,91 \\
$45-49$ & 0,98 & 0,90 & 0,92 \\
$50-54$ & 0,90 & 0,93 & 0,90 \\
$55-59$ & 0,88 & 0,96 & 0,80 \\
$60-64$ & 0,88 & 0,91 & 0,85 \\
$65-69$ & 0,83 & 0,88 & 0,89 \\
$70-74$ & 0,63 & 0,82 & 0,80 \\
$75-79$ & 0,49 & 0,77 & 0,70 \\
$80-84$ & 0,38 & 0,59 & 0,57 \\
$85-89$ & 0,30 & 0,40 & 0,38 \\
$90-94$ & 0,25 & 0,22 & 0,61 \\
$95-99$ & 0,16 & 0,09 & - \\
Más de 100 & 0,20 & - & - \\
\hline
\end{tabular}

Fuente: Elaborado a partir de los censos de población, años 1900-1920.

Especialmente significativo resulta el efecto de "generación". El motivado por la coyuntura socioeconómica, que impulsò a los trabajadores a acudir o abandonar la comarca según las, disponibilidades de empleo. Los grupos de edad 20 a 44 años $^{3}$ 
- los más activos - presentan en el ciclo estudiado un declinamiento paulatino. Hecho que provocará el enmascaramiento de la evolución natural.

Comparadas estas tasas con las correspondientes a la provincia de Murcia, resaltan aún más las características apuntadas:

TABLA XVII

TASAS DE MASCULINIDAD

EN LA PROVINCIA DE MURCIA

(1900-1920)

\begin{tabular}{cccc}
\hline GRUPOS DE EDAD & 1900 & 1910 & 1920 \\
\hline $0-4$ & 1,01 & 1,04 & 1,02 \\
$5-9$ & 1,05 & 0,99 & 1,02 \\
$10-14$ & 1,06 & 0,99 & 0,96 \\
$15-19$ & 0,91 & 0,95 & 0,87 \\
$20-24$ & 1,00 & 0,97 & 0,94 \\
$25-29$ & 0,97 & 0,96 & 0,96 \\
$30-34$ & 1,02 & 0,98 & 0,97 \\
$35-39$ & 0,94 & 0,94 & 0,94 \\
$40-44$ & 0,98 & 0,99 & 0,93 \\
$45-49$ & 0,95 & 0,96 & 0,94 \\
$50-54$ & 0,93 & 0,94 & 0,96 \\
$55-59 \cdot$ & 0,93 & 0,94 & 0,91 \\
$60-64$ & 0,95 & 0,97 & 0,93 \\
$65-69$ & 0,97 & 0,99 & 0,95 \\
$70-74$ & 0,92 & 0,97 & 0,92 \\
$75-79$ & 0,88 & 0,96 & 0,91 \\
$80-84$ & 0,82 & 0,87 & 0,86 \\
$85-89$ & 0,76 & 0,77 & 0,80 \\
$90-94$ & 0,67 & 0,69 & 0,75 \\
$95-99$ & 0,49 & 0,52 & 0,67 \\
Más de 100 & 0,54 & 0,50 & 0,16 \\
\hline
\end{tabular}

Fuente: Elaborado a partir de los censos de población, años 1900-1920. 
Los valores $(0,99$ en $1900,0,98$ en 1910 y 0,95 en 1920) son más reducidos que en Cartagena y La Unión. Los efectos de la "edad" dan la evolución general del período. La afluencia masiva de trabajadores a la cuenca cartagenera quedará diluida en el total provincial. Por su parte, las secuelas de la emigración - muy importante en los años de la guerra europea- no se traducirán en una clara alteración de las constantes. Ello nos hace pensar que se trata de un movimiento migracional de tipo familiar ${ }^{40}$.

Entre 1900 y 1920 se observa en Cartagena un relativo proceso de envejecimiento. La proporción de personas de más de 65 años pasa de 3,42 en 1900 a 3,83 en 1910 y a 3,98 en 1920. El grupo de 15 a 64 años experimenta una oscilación a la baja en 1910, recuperándose en la década siguiente. Finalmente, el estrato de 0 a 14 años tendrá una evolución inversa al anterior grupo: alza en 1910 y descenso en 1920.

40 Sobre la dinámica migratoria nacional, en estos años contamos con varias excelentes aproximaciones de conjunto. En particular NADAL, J.: La población española (siglos XVI al XX). Ariel. Barcelona. 1976, ps. 204-226; CAMpo, Salustiano del: Análisis de la población de España. Ariel. Barcelona. 1972, ps. 12?149; González-Rothvoss, Marinano: Influencia de la emigración en el crecimiento de la población española en los últimos cien años (1851-1950). Estudios Demográficos, IV (Madrid, 1959), ps. 541-570. Del mismo autor vid. un estudio con igual título en Revista Internacional de Sociología, núm. 41 (1953), ps. 61-84. Sobre las migracines exteriores existe abundante bibliografía. Nos ha resultado especialmente últil la visión de conjunto aportada por Garcia FERNÁNDEZ, Jesús: La emigración exterior de España. Barcelona. 1965. Y los demás estudios fundamentales referidos a las corrientes migratorias más directamente relacionadas con la subregión cartagenera: Rubio, Javier: La emigración española a Francia. Ariel. Barcelona. 1974, ps. 89-122. VILAR, Juan Bta.: Emigración española a Argelia (1830-1900). Colonización hispánica de la Argelia francesa. CSIC. Madrid. 1975, obra ésta que, aunque centrada en el período precedente, da la clave de los comportamientos migratorios posteriores. La proyección de esta corriente a conmienzos del siglo XX puede seguirse en el mismo autor: Crisis hispano-francesa de 1904-1907 en Argelia. Su incidencia sobre la emigración peninsular, la cuestión marroquí y el proceso de aproximación franco-española. "Awraq", 1 (Madrid, 1978), ps. 88-103. Y Los españoles en la Argelia francesa (1830-1914). Prólogo de José M. a Jover Zamora. Publ. Ministerio de A. Exteriores. Madrid. 1964 (en prensa). Los valores absolutos y porcentuales del movimiento cartagenero pueden contemplarse en Egea Bruno, P. M.: La crisis de 1917... 
TABLA XVIII

\section{ENVEJECIMIENTO DE LA POBLACION DE CARTAGENA (1900-1920)}

\begin{tabular}{crrr}
\hline GRUPOS DE EDAD & 1900 & \multicolumn{1}{c}{1910} & \multicolumn{1}{c}{1920} \\
\hline $0-14$ & 32,53 & 33,25 & 31,35 \\
$15-64$ & 64,06 & 62,90 & 64,56 \\
65 y más & 3,42 & 3,83 & 3,98 \\
\hline
\end{tabular}

Fuente: Elaborado a partir de los censos de población, años 1900-1920.

Por su parte, La Unión presenta una estructura de población mucho más joven, dadas las características esenciales que configuraron su ciclo demográfico.

TABLA XIX

ENVEJECIMIENTOO DE LA POBLACION

DE LA UNION (1900-1920)

\begin{tabular}{crrr}
\hline GRUPOS DE EDAD & 1900 & \multicolumn{1}{c}{1910} & \multicolumn{1}{c}{1920} \\
\hline $0-14$ & 36,44 & 35,64 & 38,38 \\
$15-64$ & $61-02$ & 61,65 & 59,10 \\
65 y más & 2,53 & 2,69 & 2,48 \\
\hline
\end{tabular}

Fuente: Elaborado a partir de los censos de población, años 1900-1920.

Comparando los valores de ambas poblaciones con los relativos a la provincia de Murcia, tanto Cartagena como La Unión se nos presentan como dos entidades jóvenes. 
TABLA XX

ENVEJECIMIENTO DE LA POBLACION DE LA PROVINCIA DE MURCIA (1900-1920)

\begin{tabular}{crrr}
\hline GRUPOS DE EDAD & 1900 & \multicolumn{1}{c}{1910} & 1920 \\
\hline $0-14$ & 36,25 & 36,14 & 34,03 \\
$15-64$ & 59,60 & 59,42 & 61,26 \\
65 y más & 4,13 & 4,39 & 4,56 \\
\hline
\end{tabular}

Fuente: Elaborado a partir de los censos de población, años 1900-1920.

Otro dato a tener en cuenta, por su indudable trascendencia, es la tasa de dependencia. Exceptuando a La Unión, disminuye en el intervalo 1900-1920, tanto en Cartagena como en la provincia. El incremento de la puebla minera viene explicado no por el aumento de ancianos, sino por una disminución de la po. blación potencialmente activa.

TABLA XXI

TASAS DE DEPENDENCIA (1900-1920)

\begin{tabular}{llll}
\hline POBLACION & 1900 & 1910 & 1920 \\
\hline Cartagena & 0,56 & 0,58 & 0,54 \\
La Unión & 0,63 & 0,62 & 0,69 \\
Prov. Murcia & 0,67 & 0,68 & 0,62 \\
\hline
\end{tabular}

Fuente: Elaborado a partir de los censos de población, años 1900-1920.

Con las relaciones examinadas anteriormente, estamos en condiciones de conocer las modificaciones estructurales.

La pirámide de Cartagena en 1900 se caracteriza por una disimetría favorable al sexo masculino. Fenómeno razonado por' una fuerte inmigración, particularmente visible en las entalladu- 
ras de 20 a 29 años. Igualmente, se deja sentir la emigración finisecular, coincidiendo con la crisis que afectó al sector minero, en la escala de 30 a 34 años. Ello explicará por sí solo el estrechamiento de la base. Finalmente, es de notar que en el grupo de 35 a 39 años se aprecian los efectos de otra clase inmigratoria, quedando ambos brazos equilibrados: 7,69 por ciento para el sexo masculino y 8,15 para el femenino, de ahí que podamos inducir el carácter familiar de este movimiento.

La pirámide de 1910 sigue conservando una relativa superioridad varonil. Por lo demás, destaca también el estrangulamiento de la base, determinado por la pérdida de efectivos en el grupo de 30 a 40 años.

En 1920 sobresale el abultamiento del grupo de 20 a 24 años - fruto de un nuevo vaivén migratorio - fuertemente favorable a los varones: 12,52 por ciento frente al 9,64 de las hembras. Una vez más, el estrangulamiento del grupo de 30 a 44 años provocará el estrechamiento de la base.

La estructura de La Unión en 1900 presenta las señales in. equívocas de una fuerte inmigración finisecular, particularmente perceptible en el escalón de los 25 a los 29 años, pues representa un porcentaje sobre el total de la población relativamente importante: 9,74 por ciento para los varones y 9,97 para las hembras. El equilibrio entre los sexos caracteriza el fenómeno con el tilde de grupo familiar. La importante protuberancia de la entalladura señalada tiene su repercusión más inmediata y clara en el incremento de la base.

En 1910 la puebla minera ya acusa los efectos de la crisis económica, produciéndose una pérdida de efectivos que afectan, sobre todo, al sexo masculino. El resultado no es otro que la subsiguiente disimetría del diagrama favorable al sexo femenino. La integración porcentual de estos no ofrece dudas al respecto: 49,85 por ciento para los varones y 50,14 para las hembras. Los desequilibrios alcanzan mayor importancia, como era lógico suponer, en los grupos potencialmente más activos.

La tendencia migratoria iniciada en 1910 se confirmaría en el decenio siguiente. La disimetría entre los brazos de la pirámi- 
GRAFICO 2: Pirámides de edad en Cartagena
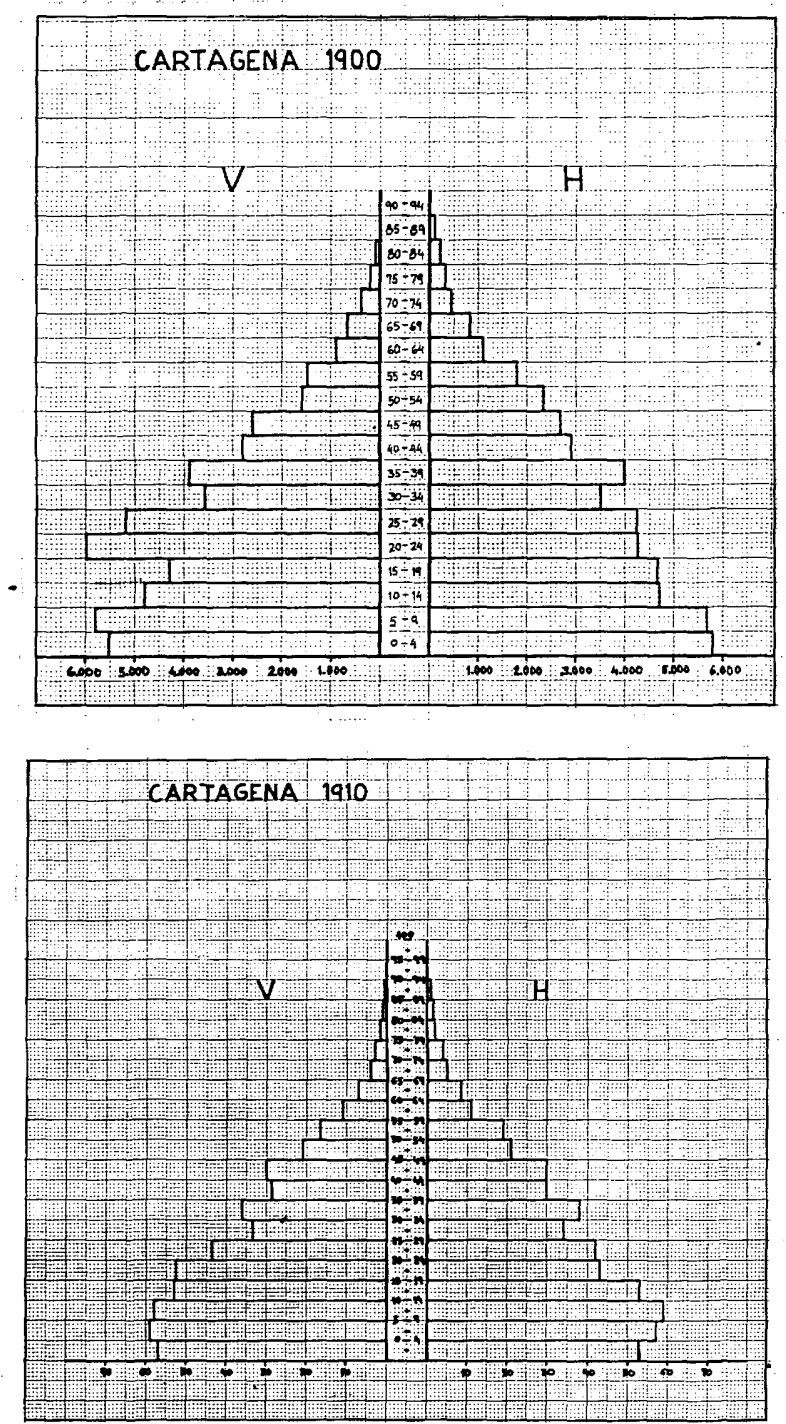


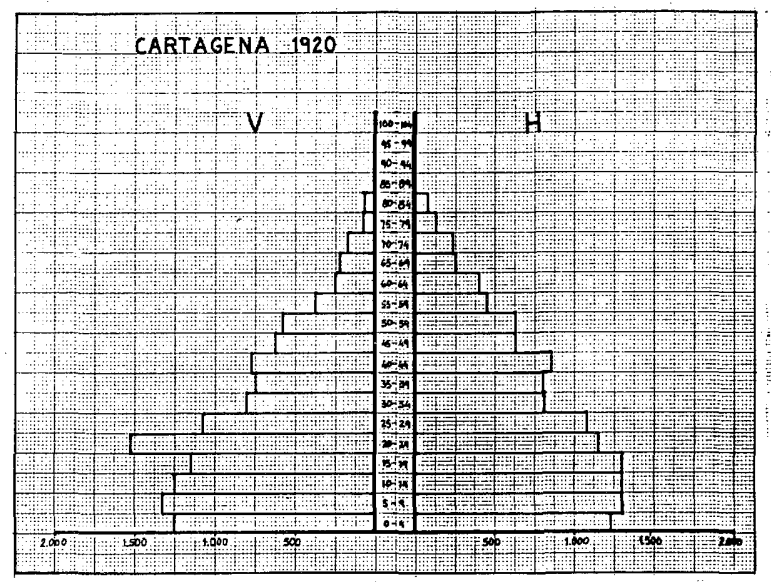

GRAFICO 3: Pirámides de edad en La Unión

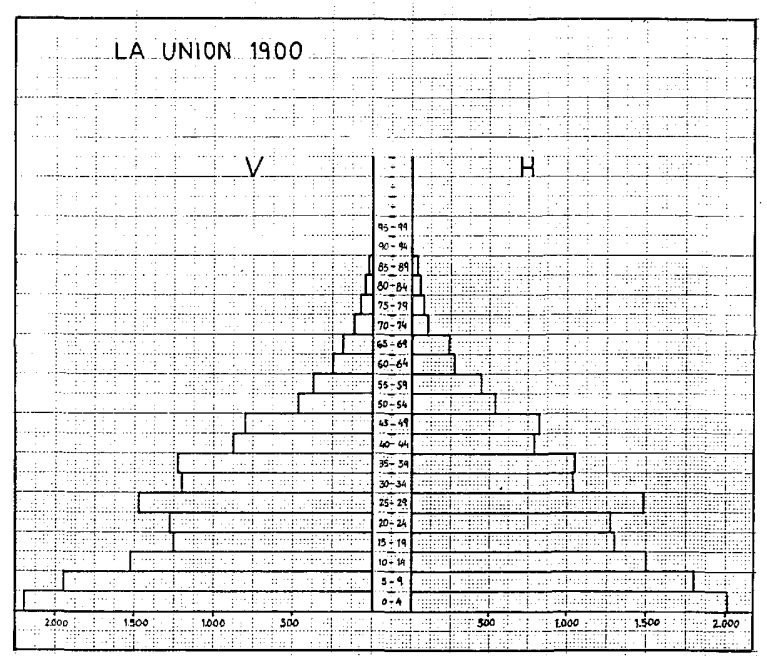



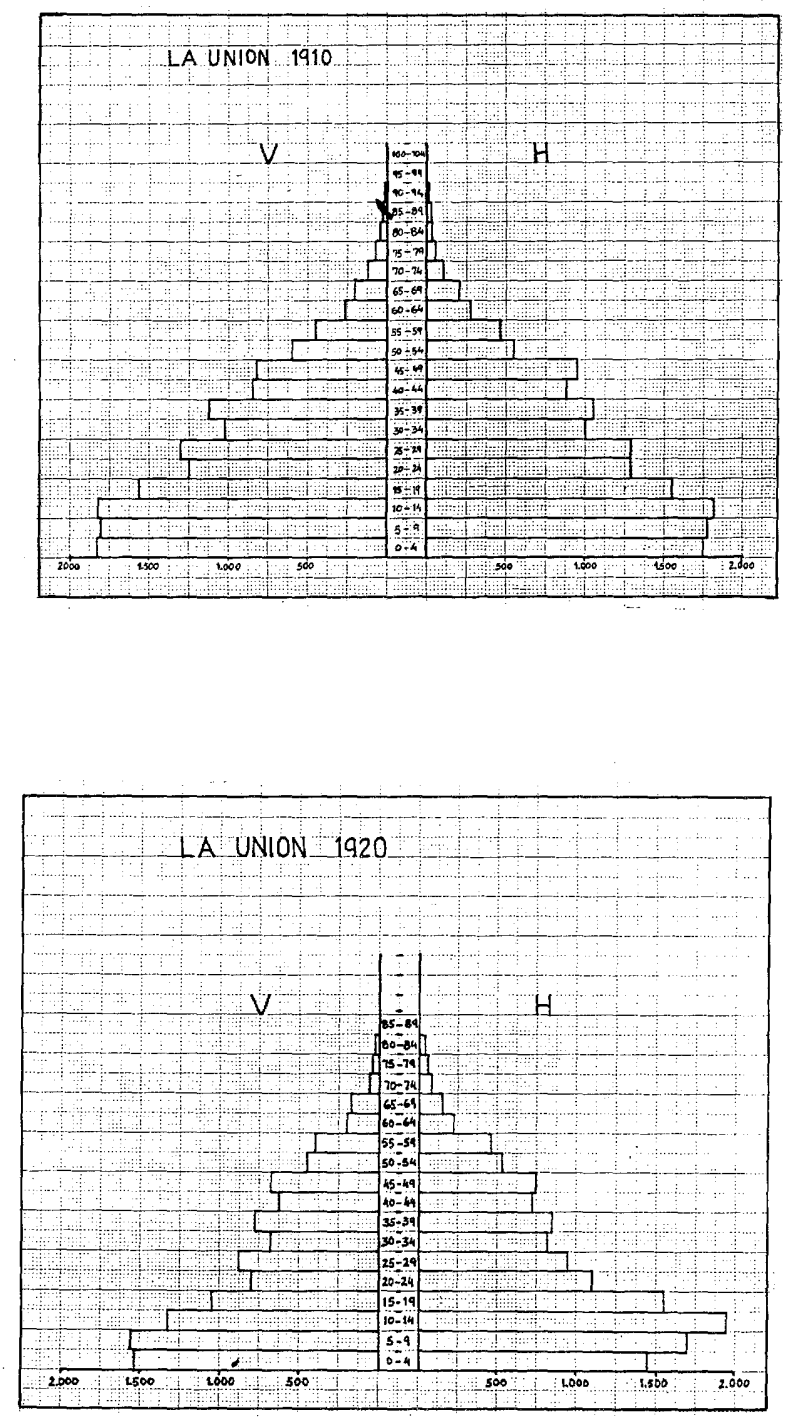
GRAFICO 4: Pirámides de edad en la provincia de Murcia
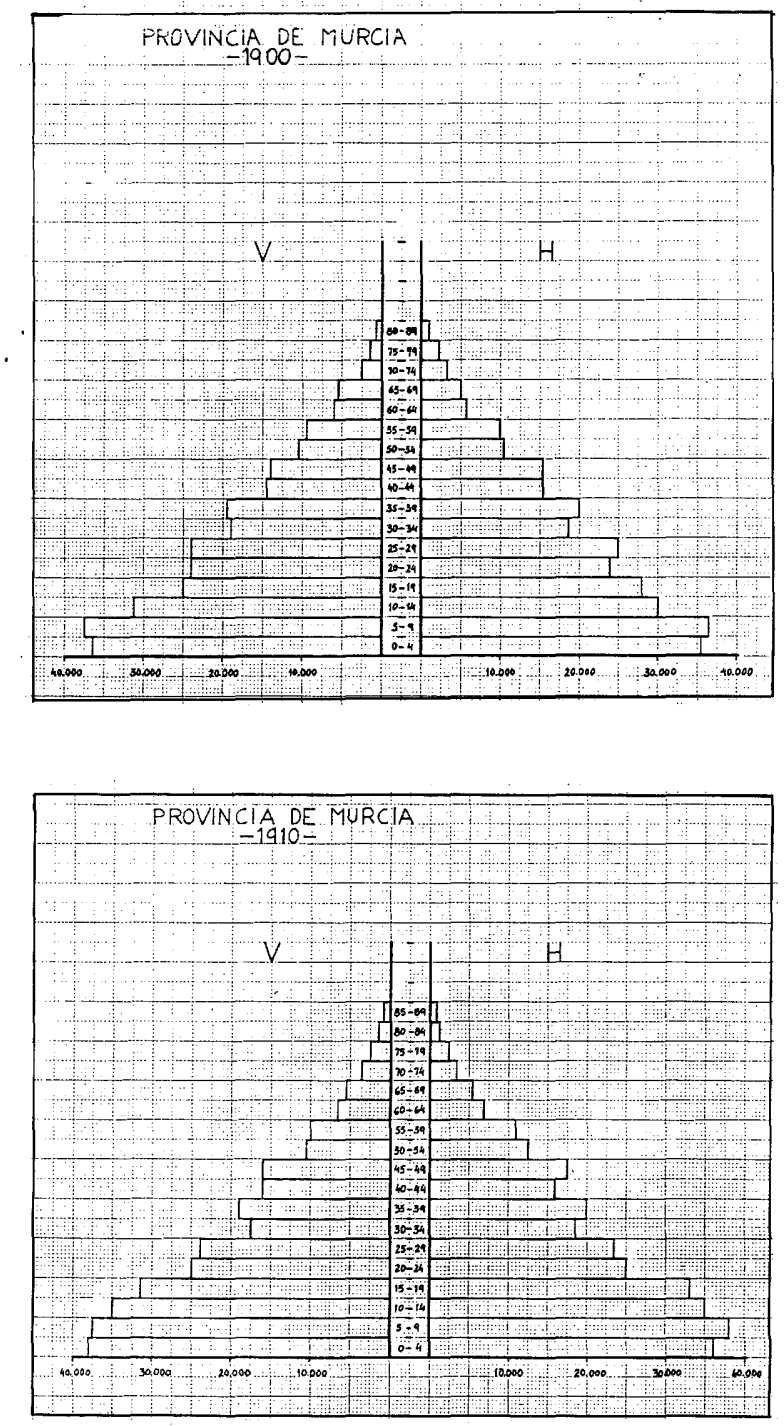


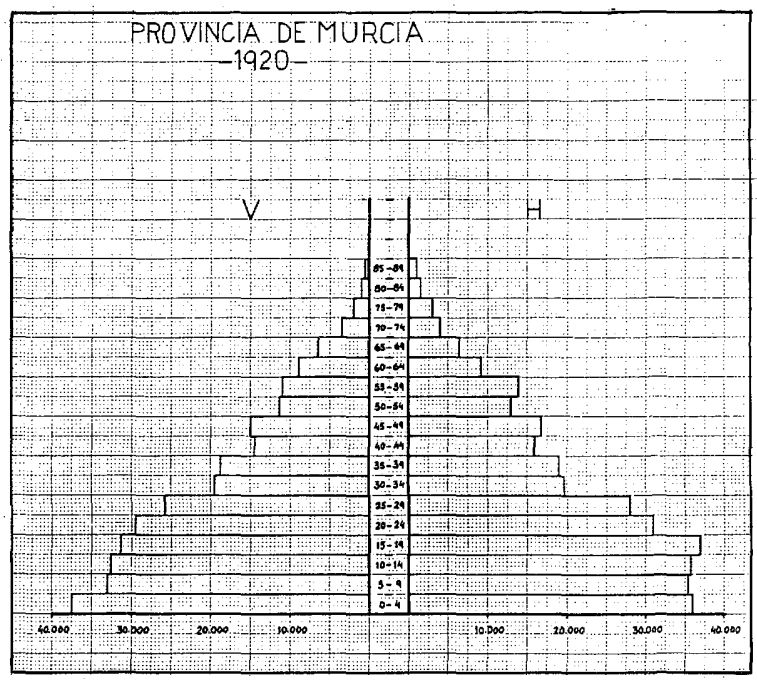

de ya es importante a tenor de los porcentajes para cada uno de los sexos: 45,54 por ciento para los varones y 54,45 para las hembras. La emigración afectará sobre todo a los grupos de edades más fértiles, es decir de 20 a 34 años. La consecuencia no puede ser otra que el estrechamiento de la base.

A excepción de la usex ratio" de los escalones 10 a 14 años, anómala y de causas desconocidas, entre las restantes sobresale la acusada hinchazón femenina en el grupo de 15 a 24 años. La emigración en estas edades debió ser de varones solteros. En los siguientes estratos las diferencias son más cortas, por lo que es dado pensar que el movimiento migracional se unieron familias enteras.

Comparando las estructuras cartageneras y unionenses con la provincial acaba por revelarse la dinámica demográfica a que estuvo sometida nuestra área de estudio, al girar su economía sobre el eje único de la minería. El brusco basculamiento de ésta provocará los fenómenos descritos. La provincia, con unas bases económicas menos ciclotímicas, amortiguará mejor el efecto de vaso comunicante economía-demografía. 
La pirámide de la población murciana en 1900 refleja una situación de equilibrio. Los varones representan el 49,80 por ciento del total frente al 50,19 de las hembras. La diferencia más aguda se establece para el grupo de 35 a 39 años, pero es muy leve. La pérdida de efectivos masculinos sólo alcanza el 0,31 por ciento, si bien es suficiente para provocar el estrangulamiento de la base.

En 1910, Murcia mantiene una estructura muy similar a la del comienzo de la centuria. La crisis económica fue predominantemente minera, de ahí que la "sex ration provincial no sufra variaciones sensibles. El 49,51 por ciento de los efectivos poblacionales corresponde a los varones y el 50,48 a las hembras. El mayor estrangulamiento sigue correspondiendo a los núcleos integrantes de la emigración, la entalladura de los 30 a los 34 años, que al quedar equilibrados entre ambos brazos debió constituir un fenómeno familiar.

La contienda europea de 1914-1918 y la crisis de postguerra afectaron profundamente a la economía murciana, en particular al agro, que se desprendió de buena parte de su abundante población desempleada ${ }^{41}$.

Por todo ello, en 1920 la disimetría entre los sexos resulta ya acusada. El 48,92 por ciento de los efectivos corresponde a los varones y el 51,07 a las hembras. El estrangulamiento de los escalones 30 a 44 años es resultado de la superposición de tres oleadas emigratorias: finisecular, bélica y postbélica.

\section{CONCLUSIONES}

Una de las manifestaciones más elocuentes de los profundos cambios que se operan en el seno del capitalismo español durante Ja guerra europea es, sin duda, la intensidad y la dinámica de los movimientos de población.

41 Cfr. Egea Bruno, P. M.: La agricultura murciana de exportación durante la guerra europea (1914-1918). En preparación. 
Las intrínsecas relaciones entre la economía y la demografía no hacen en nuestra zona sino confirmarse. El efecto de vaso comunicante es obvio. La dinámica de la primera se proyectará, con precisión milimétrica, sobre la segunda. El vaivén ocupacional del empleo -con su indicador real más claro: el movimiento migratorio- modelará la estructura de la población.

Cartagena en 1900 ofrece el sesgo típico de una fuerte inmigración. Las tasas de masculinidad superan la unidad, elevándose en aquellas cohortes propiamente migratorias. El proceso de recepción se paralizará en 1910, coincidiendo con el inicio de la crisis minera, reconvirtiéndose la ecuación a partir de entonces. La emigración y la declinación económicà marcharán paralelas.

Mucha más claridad al respecto ofrece el caso de la puebla minera, al girar toda su economía sobre el único eje de la minería. Talón de Aquiles de todo el andamiaje social. Herido éste, no tardará en precipitarse todo el edificio.

La Unión, que ya arroja emigrantes desde el comienzo de la centuria, al final del período ni siquiera logra retener el 50 por ciento de sus efectivos. El tilde del despueble se reflejará en todas las manifestaciones demográfica. La tasa de masculinidad ofrece una progresiva caída. Igual sucederá con las de dependencia, que acusan sobremanera la disminución de la población potencialmente activa.

Fenómenos que contrastarán, en todos los casos, con la dinámica demográfica provincial. Sus bases económicas, sustentadas en una estructura de larga duración, apenas modificarán la evolución poblacional. 
AC: Acta capitular

ACCINC: Archivo Cámara Comercio, Industria y Navegación

AJPMM: Archivo Jefatura Provincial de Minas de Murcia

AMLU: Archivo Municipal de La Unión

BOMM: Boletín Oficial de Minas y Metalurgia

BOPM: Boletín Oficial de la Provincia de Murcia

CSIC: Consejo Superior de Investigaciones Científicas

DGE: Dirección General de Estadística

DGIGE: Dirección General del Instituto Geográfico

y Estadístico

DGMG: Dirección General de Minas y Combustibles

GMC: Gaceta Minera y Comercial

INE: Instituto Nacional de Estadística

IRS: Instituto de Reformas Sociales

LA: Libro de Acuerdos

LRSC: Libro Registro de Salida de Correspondencia

REM: Revista de Economía y Hacienda

RMM: Revista Minera y Metalúrgica

RMMI: Revista Minera, Metalúrgica y de Ingeniería

SDMB: Sindicato para el Desagüe de las Minas del Beal

SE: Sesión Extraordinaria 